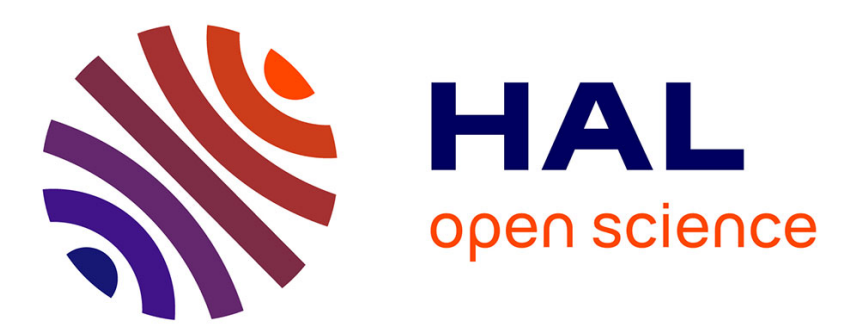

\title{
Angle-dependent ray tracing simulations of reflections on pyramidal textures for silicon solar cells
}

Vincent Magnin, Joseph El Harari, Mathieu Halbwax, S Bastide, D Cherfi, Jean-Pierre Vilcot

\section{- To cite this version:}

Vincent Magnin, Joseph El Harari, Mathieu Halbwax, S Bastide, D Cherfi, et al.. Angle-dependent ray tracing simulations of reflections on pyramidal textures for silicon solar cells. Solar Energy, 2014, 110, pp.378 - 385. 10.1016/j.solener.2014.09.025 . hal-01403918

\section{HAL Id: hal-01403918 https://hal.science/hal-01403918}

Submitted on 28 Nov 2016

HAL is a multi-disciplinary open access archive for the deposit and dissemination of scientific research documents, whether they are published or not. The documents may come from teaching and research institutions in France or abroad, or from public or private research centers.
L'archive ouverte pluridisciplinaire HAL, est destinée au dépôt et à la diffusion de documents scientifiques de niveau recherche, publiés ou non, émanant des établissements d'enseignement et de recherche français ou étrangers, des laboratoires publics ou privés.

$$
\text { Copyright }
$$




\title{
Angle-dependent Ray Tracing Simulations of Reflections on Pyramidal Textures for Silicon Solar Cells
}

\author{
V. Magnin ${ }^{\mathrm{a} *}$, J. Harari ${ }^{\mathrm{a}}$, M. Halbwax ${ }^{\mathrm{a}}$, S. Bastide ${ }^{\mathrm{b}}$, D. Cherfi ${ }^{\mathrm{a}}$, J.-P. Vilcot ${ }^{\mathrm{a}}$ \\ ${ }^{a}$ Institut d'électronique de microélectronique et de nanotechnologie, UMR CNRS 8520, \\ Université Lille 1 Sciences et Technologies, Avenue Henri Poincaré, CS 60069, 59652 \\ Villeneuve d'Ascq cedex, France \\ ${ }^{b}$ Institut de Chimie et Matériaux Paris-Est, UMR CNRS 7182, 2-8 rue Henri Dumant, \\ 94320 Thiais, France
}

\begin{abstract}
Pyramidal textures are commonly used to reduce reflections from silicon solar cells and improve light absorption by light trapping. They are generally modelled or characterized under normal incidence. In this work, a monolayer 3D ray tracing program taking into account the polarisation of light have been developed, validated and used to compute the directionalhemispherical reflectance versus the azimuth and incidence angles for both regular upright pyramids and inverted ones, with (111) facets. Results are given for a wavelength of $0.7 \mu \mathrm{m}$. They show that this reflectance is not minimal at normal incidence but for an incidence angle near $20^{\circ}$ and that upright pyramids can have a lower hemispherical reflectance than inverted ones for incidence angles in the middle range. The bihemispherical reflectance is $19.6 \%$ for regular upright pyramids and $20.7 \%$ for inverted ones. The effect of the pyramids aspect ratio on the hemispherical reflectance at normal incidence is also studied. This reflectance decreases with the aspect ratio of both textures. Above an aspect ratio of 0.51 , inverted pyramids have a lower hemispherical reflectance. But their bihemispherical reflectance is lower only for aspect ratios below 0.23 .
\end{abstract}

Keywords: texture, ray tracing, reflectance, solar cell

\footnotetext{
*Corresponding author. Tel.: +33 320197967 .

Email address: vincent.magnin@iemn.univ-lille1.fr (V. Magnin $\left.{ }^{\mathrm{a}}\right)$

URL: http://www.iemn.univ-lille1.fr/ (V. Magnin ${ }^{\mathrm{a}}$ )
} 


\section{Introduction}

Surface texturing is commonly used to reduce reflections from silicon solar cells and improve light absorption by light trapping (Razykov et al., 2011). In particular, the record monocrystalline silicon cell (25\% efficiency) has an inverted pyramid surface texture (Zhao et al., 1998; Green et al., 2013). Pyramidal textures are typically produced by etching (100)-oriented monocrystalline wafers in an alkaline solution such as $\mathrm{KOH}$ or $\mathrm{NaOH}$ (Moreno et al., 2014). The etching being anisotropic gives theoretically (Baker-Finch and McIntosh, 2013) square-based pyramids with (111) facets inclined by $54.74^{\circ}$ from the horizontal plane.

The efficiency of surface textures is generally evaluated by characterizing or modelling under normally incident light, and it is well known that in those conditions inverted pyramids have a lower reflectance than upright ones (Baker-Finch and McIntosh, 2011). Sometimes the zenith incidence angle is considered (Rodríguez et al., 1997; Yu et al., 2003; Byun et al., 2012; McIntosh and Baker-Finch, 2012), but we found very few studies considering both zenith and azimuth incidence angles (Parretta et al., 1999; Gjessing et al., 2011). In this paper, we study the directional-hemispherical reflectance of regular upright and inverted pyramids, taking into account both angles, and their bihemispherical reflectance (i.e. hemispherical-hemispherical reflectance, the first adjective relating to the collimation of the source, the second of the detector (Nicodemus et al., 1977; Hapke, 2012)).

First, the development and the validation of a 3D ray tracing model taking into account polarisation are presented. It is then used to compute and study the directional-hemispherical reflectance of regular upright and inverted pyramids versus zenith and azimuth angles. Then we compare these two textures under diffuse light by computing their bihemispherical reflectance.

Although chemical etching is imposing the base angle of pyramids, it could be interesting to obtain pyramids with a higher base angle in order to reduce reflections and to increase light trapping (Hua et al., 2010). We therefore in a second part study the effect of the aspect ratio of both types of pyramids on their directional-hemispherical and bihemispherical reflectances. 


\section{Simulation}

\subsection{Model description}

A ray tracing program was developed in Fortran using the test driven development methodology (Gagliardi, 2007), which is well adapted to scientific computing programs: for each needed function, automated tests are first written. Then the function is written, with the simplest possible code that can pass the tests. Then the code is refactored or optimised if needed, and the tests launched. The development process continues with another function. The automated tests allow the developer to code with more confidence. System tests can be added when the model is functional, in order to avoid any regression in the code. Following this methodology, we gradually developed a 2D model, then a 3D one, and finally we introduced a rigorous approach of the polarisation of light.

Indeed, a 3D model is necessary to study a texture illuminated under any incidence angle and azimuth angle, and the polarisation must be taken into account to study inverted pyramids because reflections on orthogonal facets produce polarisation rotations (Trupke et al., 2006; Baker-Finch and McIntosh, 2011). Our model can simulate any surface that can be mathematically described as a $z=f(x, y)$ continuous function. This surface must be meshed with triangles: in the case of a square-based pyramids texture, each pyramid is simply meshed with four triangles. In this paper, unless otherwise specified, the simulated area is $100 \times 100 \mu \mathrm{m}$, covered by one hundred $10 \times 10 \mu \mathrm{m}$ pyramids (Fig. 1), when computing the directional-hemispherical reflectance, and $400 \times 400 \mu \mathrm{m}$ for bihemispherical reflectance. These pyramids have a height or depth of $7.07 \mu \mathrm{m}$, their facets being inclined by $54.74^{\circ}$ from the horizontal plane, although recent studies have confirmed that in practice that angle can be slightly lower (Yang et al., 2013; Baker-Finch and McIntosh, 2013), a point that will be discussed later. The dimensions of the pyramids being much greater than the wavelengths absorbed by silicon, the geometric optics approximation can be considered valid. Under this hypothesis, the optical behaviour does not depend on the width of the pyramids but only on the inclination angle of their facets (Byun et al., 2011; Lien et al., 2012).

Each ray direction is defined using spherical coordinates as shown in Fig. 1. Light is considered unpolarised: each launched ray has its own complex electric field vector, orthogonal to the propagation direction (the medium is considered linear and isotropic), oriented in space using a random angle in the $0-2 \pi$ range and defined as a unit vector. The reflected elec- 
tric field vector is computed using the three-by-three polarisation ray tracing matrix as extensively described by Yun et al. (2011) and resumed by BakerFinch and McIntosh (2011). This matrix is the product of three matrices: a first orthogonal matrix to transform between the global coordinate basis and the local s-p coordinates, the reflection Jones matrix and a third orthogonal matrix to transform between the local s-p coordinates and the global coordinate basis. The Jones Matrix includes the complex amplitude Fresnel coefficients computed for $\mathrm{s}$ and $\mathrm{p}$ polarisations (Hapke, 2012). The $\cos \left(\theta_{i}\right)$ geometric factor of the solar energy actually captured under an incidence angle $\theta_{i}$ is omitted to better compare the actual light-trapping efficiency of the textures at various azimuth and incidence angles (Gjessing et al., 2011).

In each simulation, one million incident rays are generated at random $(x, y)$ positions over the surface. For studies with high incidence angles, these positions are restricted to the central pyramid in order to limit the number of rays exiting the computing window. For each ray, the algorithm searches the nearest intersected triangle, computes geometrically the incidence and reflection angles, then the reflected energy, until the ray quits the computing window. The number of bounces is recorded for statistics.

Transmitted rays are considered totally absorbed by silicon. Results computed under this hypothesis are generally in good agreement with measurements until a wavelength of $1 \mu \mathrm{m}$. Beyond, the absorption depth in silicon becomes rapidly greater than the thickness of the substrate and light can be easily reflected by the back surface one or several times and finally escape by the front surface.

The main output of the program is the directional-hemispherical reflectance at the considered wavelength. To lighten the text of this paper we will use the term hemispherical reflectance in the text and reflectance in the figures. Other outputs consist of the percentage of single bounces, double bounces, etc., the average number of bounces, and if necessary the complete path followed by each incident ray (directions, coordinates of each reflection point, facets numbers, energy, polarisation). The generated surface is recorded in a file using the STL (STereoLithography) format that can be imported in a $3 \mathrm{D}$ visualisation software (Fig. 1) or even printed with a 3D printer to obtain a macroscale prototype.

The complex refractive indexes of intrinsic silicon in the $0.25 \mu \mathrm{m}-1.45 \mu \mathrm{m}$ wavelength range are taken from the tabulation published by Green (2008). Unless otherwise specified, all results in this paper are given for the $\lambda=$ $0.7 \mu m$ wavelength. That will be discussed in the results section. The stan- 
dard deviation on the computed hemispherical reflectance expressed as a percentage has been evaluated to 0.005 by launching the same computing one thousand times with one million rays.

\subsection{Model validation}

The model was validated first by computing well-known results. For a perfectly plane surface the computed hemispherical reflectance is $33.7 \%$ under normal incidence, each ray being reflected only once. In the case of regular upright pyramids and normal incidence, $88.8 \%$ of normally incident rays suffer a double bounce and $11.1 \%$ a triple bounce (Baker-Finch and McIntosh, 2011), resulting in a 2.11 mean number of bounces and a $11.45 \%$ hemispherical reflectance. In the case of inverted pyramids, $59.2 \%$ of normally incident rays suffer a double bounce and $40.8 \%$ a triple bounce as obtained with OPAL 2 free online software (McIntosh and Baker-Finch, 2012), resulting in a 2.41 mean number of bounces and a $8.70 \%$ hemispherical reflectance. As is well known, inverted pyramids are therefore better than upright pyramids when illuminated under normal incidence (Fig. 2). The angles of reflection for each possible path were also verified (Baker-Finch and McIntosh, 2011). We also compared our results with simulation and experimental data published in the literature (Byun et al., 2011; Lien et al., 2012) for bare silicon and upright pyramids. It should be noted that it is current in the literature to compare the modelling of regular upright pyramids with measurements of random upright pyramids, because a regular texture is far easier to mesh.

Secondly, the simulation results were compared with the first experiments made in our laboratories on that subject. Inverted pyramids were etched on silicon (Fig. 3). The samples were p-type (boron doped) Czochralski silicon wafers with $5-10$ S.cm resistivity, (100) orientation and $300 \mu \mathrm{m}$ thickness. Their front side was polished. Silicon nitride $\left(\mathrm{SiN}_{\mathrm{x}} \mathrm{H}_{\mathrm{y}}\right)$ was first deposited by low-pressure chemical vapor deposition (LPCVD) on both sides. In a second step, $9 \mu \mathrm{m}$ square patterns with $1 \mu \mathrm{m}$ resist gaps were realized on front side using electron-beam lithography. Reactive-ion etching has been used to transfer the resist pattern into the $\mathrm{SiN}_{\mathrm{x}} \mathrm{H}_{\mathrm{y}}$ film before this latter was also removed using a RIE process. $\mathrm{KOH}$ wet etching was then carried out at $80^{\circ} \mathrm{C}$. A rotating $(150 \mathrm{rpm})$ magnetic stirrer was used during this etching step in order to obtain a uniform etch. The inverted pyramids measured width is $9.8 \mu \mathrm{m}$. The surface topography was characterized by scanning electron microscopy (Fig. 3). The total reflectivity was measured using a 
Hitachi UVVISNIR 4001 spectrophotometer equipped with an integrating sphere in the $0.35-1 \mu \mathrm{m}$ wavelength range at room temperature.

Simulation and experimental results are compared on Fig. 2. Concerning polished silicon, measurements and simulation are in very good agreement. Concerning inverted pyramids, the measured hemispherical reflectance is $9.8 \%$ when the computed value is $8.7 \%$ at a wavelength of $0.7 \mu \mathrm{m}$. A great part of the difference can be explained by the presence of a $200 \mathrm{~nm}$ wide planar zone between adjacent pyramids (see Fig. 3), due to the technological process. If we compute the weighted sum of the hemispherical reflectances of the pyramidal part and of the planar fraction, we obtain a $9.68 \%$ hemispherical reflectance, which is very close to measurements. However, it can not explain the greater difference in the UV wavelengths. At a wavelength of $0.35 \mu \mathrm{m}$ the computed hemispherical reflectance is $21.5 \%$ and the measured one is $26.2 \%$. This gap may come from a strong increase of the imaginary part of the complex optical index due to the doping of the silicon substrate $\left(2 \times 10^{15} \mathrm{~cm}^{-3}\right)$, the model using the optical index of intrinsic silicon (Green, 2008). This hypothesis is consistent with the fact that the gap is lower for the plane surface, where the rays are bouncing only once.

\section{Results and discussion}

\subsection{Influence of the incidence and azimuth angles}

The mean number of bounces and the hemispherical reflectance of surfaces textured with regular upright pyramids (Fig. 4 and 5) and regular inverted pyramids (Fig. 6 and 7) have been computed for incidence angles between 0 and $90^{\circ}$ and azimuth angles between 0 and $45^{\circ}$ because of the four-fold rotational symmetry. The computing time for each kind of pyramids was four days on a personal computer. Note that at incidence angles beyond $80^{\circ}$, the simulation window have been enlarged to $1000 \times 1000 \mu \mathrm{m}$ to avoid rays being lost outside that window. This can be the case for upright pyramids, rays being injected just above the plan containing the top of the pyramids, those travelling between two rows of pyramids (near $0^{\circ}$ azimuth angle) at high incidence angle can cross the window before reflecting upon a pyramid facet (Fig. 1).

Figures 4 and 5 show that the azimuth angle can have a much more significant effect on the hemispherical reflectance and the mean number of bounces in the case of upright pyramids, for incidence angles above $40^{\circ}$. There is even a dramatic peak of hemispherical reflectance for the $0^{\circ}$ azimuth angle and 
very high incidence angles (Fig. 5), because an important proportion of rays travelling between two rows of pyramids are reflected upward only once on the lateral pyramid facets at grazing incidence, which implies that Fresnel coefficients are very high. Some computations were made at other wavelengths than $\lambda=0.7 \mu \mathrm{m}$ and showed that the global shape of the 3D reflectance plots were similar but with a shift toward higher or lower reflectances. Indeed, the values of the Fresnel coefficients are wavelength dependent but not the geometrical paths followed by the reflected rays. Which also means that the plots concerning the mean number of bounces are not dependent on wavelength.

Another result is that for upright pyramids the hemispherical reflectance is not minimal at normal incidence but between $15^{\circ}$ and $20^{\circ}$, depending on the azimuth angle. Its minimal value is $10.6 \%$ for a zero azimuth angle and a $19^{\circ}$ incidence angle. It corresponds to the maximum of the mean number of bounces, whose value is 2.22 . For inverted pyramids, the effect is smaller, the minimal hemispherical reflectance being $8.58 \%$ and the mean number of bounces being 2.48 for a $45^{\circ}$ azimuth angle and a $22^{\circ}$ incidence angle.

It is well known that at normal incidence inverted pyramids are better than upright ones. But this is not the case in all lighting conditions. The difference of hemispherical reflectance between upright and inverted pyramids is plotted Fig. 8. The upright pyramids hemispherical reflectance is higher at low and high incidences angles but can be lower in the middle range. For example, our results show that for a zero azimuth angle, upright pyramids have a lower hemispherical reflectance for incidence angles between $26^{\circ}$ and $85^{\circ}$. At a $72^{\circ}$ incidence angle, its value is $19.8 \%$ for upright pyramids and $30.4 \%$ for inverted pyramids. It corresponds to the trough that can be seen in Fig. 5. For a $45^{\circ}$ azimuth angle, upright pyramids are better between $37^{\circ}$ and $57^{\circ}$ incidence angles, but the difference is far lower. At a $53^{\circ}$ incidence angle, the hemispherical reflectance is $25.0 \%$ for upright pyramids and $25.6 \%$ for inverted pyramids.

To compare globally these two textures we have computed their bihemispherical reflectance by a Monte Carlo method. The azimuth angle of each ray is randomly drawn between 0 and $360^{\circ}$ and the incidence angle between 0 and $90^{\circ}$. For upright pyramids, the bihemispherical reflectance is then $19.6 \%$ and the mean number of bounces is 1.70 , but for inverted pyramids the results are respectively $20.7 \%$ and 1.74 . For such an isotropic diffuse light, upright pyramids are therefore better than inverted ones. The bihemispherical reflectance can give clues on the performances of solar cells under 
diffuse light (cloud-covered sky for example) (Parretta et al., 2003; Kelly and Gibson, 2011).

But of course, in the case of a solar cell module the encapsulant and the glass are strongly limiting the maximum incidence angle on the silicon surface. If the encapsulant optical index is 1.5, the maximum refraction angle will be $41.8^{\circ}$. Moreover at high incidences, most of the light incident on the module will be reflected at the air/encapsulant interface. For those reasons, a multilayer model would be necessary to take into account rigorously these effects.

\subsection{Influence of the aspect ratio}

In geometrical optics, the hemispherical reflectance of a texture depends on the complex optical index of the material, the reflection angles and the number of reflections. For a given material, the optimisation must therefore concern the geometry of the texture. For example, although alkaline etching of silicon imposes a pyramid slope near the theoretical $54.74^{\circ}$ angle, alternative methods could be used to obtain pyramids or other patterns with different slopes, for example femtosecond laser structuration (Crouch et al., 2004), reactive ion etching (Yoo, 2010) or nanoimprint lithography (Yu et al., 2003). Indeed, higher aspect ratios would have some advantages in the case of solar cells: there would be more light trapped by reflections on the encapsulant/semiconductor interface and the path length of rays would be extended, the absorption of infrared light would thus be improved (BakerFinch and McIntosh, 2013). In this section, we study the effect of the aspect ratio (height over width), i.e. the slope of upright and inverted pyramids on the hemispherical reflectance of the texture. Note that a $54.74^{\circ}$ slope corresponds to a 0.707 aspect ratio, the base angle $\alpha$ being related to the height $h$ and the width $w$ of the pyramids by

$$
\alpha=\arctan \left(2 \cdot \frac{h}{w}\right)
$$

The pyramids width is fixed to $10 \mu \mathrm{m}$ and their height or depth varies in the $0-25 \mu \mathrm{m}$ range, corresponding to an aspect ratio in the $0-2.5$ range. They are illuminated at normal incidence at $\lambda=0.7 \mu \mathrm{m}$. The computed hemispherical reflectance and the mean number of bounces of regular upright and inverted pyramids versus their aspect ratio are shown Fig. 9 and 10. Inverted pyramids give a lower hemispherical reflectance for aspect ratios above 0.51 , and upright pyramids are better in the $0.29-0.51$ range (Fig. 9). 
Concerning upright pyramids, the mean number of bounces versus aspect ratio is a step curve, because new paths with more bounces appear at discrete values of the aspect ratio (Fig. 10). For inverted pyramids the curve is smoother, with a step ending at a 0.29 aspect ratio. And above a 0.51 aspect ratio, corresponding to a base angle of $45.6^{\circ}$, the mean number of bounces on inverted pyramids is always higher than on upright ones.

It can be noted that the mean number of bounces is not sufficient to characterize the two types of surfaces, because the aspect ratio determines the possible trajectories of the rays, and therefore the Fresnel coefficients via the incidence angles. And it must be recalled that the reflectance results are given at $\lambda=0.7 \mu \mathrm{m}$. Some computations were made at other wavelengths but are not presented, the global shape of the curves being similar but with a shift toward higher or lower reflectances.

We have also computed for both upright and inverted pyramids the bihemispherical reflectance versus aspect ratio. The results show that inverted pyramids have a very slightly lower bihemispherical reflectance up to an aspect ratio of 0.23 and always a higher one above.

Some experimental studies have shown that the base angle of pyramids can be lower than the theoretical $54.74^{\circ}$ angle (Baker-Finch and McIntosh, 2013; Yang et al., 2013), being around $52^{\circ}$ for regular inverted pyramids and $50-52^{\circ}$ for random upright pyramids. In our study, the computed hemispherical reflectance for a 0.6 aspect ratio $\left(50^{\circ}\right.$ base angle) is $12.2 \%$ for upright pyramids and $10.7 \%$ for inverted pyramids. But we have not taken into account the fact that upright pyramids can moreover not being really square-based (Baker-Finch and McIntosh, 2013).

A limitation of this study on the effect of the aspect ratio is that the transmitted rays are supposed to be totally absorbed by silicon. A more rigorous approach would require a multilayer ray tracing model because some of these rays can exit from silicon, especially for high aspect ratios, for rays intersecting the region around the top of a pyramid or for infrared wavelengths. But this problem is quite limited by the light trapping effect, due to the total internal reflections, except for infrared wavelengths.

\section{Conclusions}

We have developed, using a test driven development methodology, a 3D ray tracing program taking into account the polarisation of light that can compute the reflectance of a textured surface, in the limits of geometrical 
optics. It was validated using both literature and measurements on silicon with pyramidal textures fabricated in our laboratories.

Using this model, we have computed the directional-hemispherical reflectance versus the azimuth and incidence angles for both regular upright and inverted pyramids, with (111) facets, and we have presented the results at a wavelength of $0.7 \mu \mathrm{m}$. A first result is that the hemispherical reflectance is not minimal at normal incidence but for an incidence angle near $20^{\circ}$ for both textures. A second result is that upright pyramids can have a lower hemispherical reflectance than inverted ones for incidence angles in the middle range. We have also computed the bihemispherical reflectance, by simulating an hemispherical diffuse lighting, and obtained $19.6 \%$ for regular upright pyramids and $20.7 \%$ for inverted ones. These results show that in terms of reflectance of a bare textured silicon surface, inverted pyramids are not necessarily always more efficient in real world conditions.

In the second part of this work, we explored the effect of the pyramids aspect ratio on the hemispherical reflectance at normal incidence. The mean number of bounces increases and the hemispherical reflectance decreases with the aspect ratio of both upright and inverted pyramidal textures. At a wavelength of $0.7 \mu \mathrm{m}$, above an aspect ratio of 0.51 , corresponding to a base angle of $45.6^{\circ}$, inverted pyramids have a lower reflectance. But in the case of an hemispherical lighting, the bihemispherical reflectance of inverted pyramids is lower only for aspect ratios below 0.23 .

Further work will involve the modelling and optimisation of other geometrical patterns that could be fabricated by new technological processes. We also plan to develop a multilayer ray tracing model to take account light trapping effects in the substrate, the effect of the encapsulant and glass of a module, and of an anti-reflection coating.

\section{Acknowledgements}

This work was supported by the DEFI ENRS CNRS contract PRONOSTIQUES. The authors would also like to thank the Polytech Lille engineering school for the use of its computing power.

\section{References}

Baker-Finch, S., McIntosh, K., 2013. Reflection distributions of textured monocrystalline silicon: Implications for silicon solar cells. Progress in Photovoltaics: Research and Applications 21 (5), 960-971. 
Baker-Finch, S. C., McIntosh, K. R., 2011. Reflection of normally incident light from silicon solar cells with pyramidal texture. Progress in Photovoltaics: Research and Applications 19 (4), 406-416.

Byun, S. J., Byun, S. Y., Lee, J., Kim, J. W., Lee, T. S., Cho, K., Sheen, D., Tark, S. J., Kim, D., Kim, W. M., 2011. Analysis of light trapping effects in si solar cells with a textured surface by ray tracing simulation. Current Applied Physics 11 (4 SUPPL.), S23-S25.

Byun, S. J., Byun, S. Y., Lee, J., Lee, T. S., Kim, W. M., Cho, K., Sheen, D., Tark, S. J., Kim, D., 2012. High-efficiency grid-type si solar cell structure. Journal of the Korean Physical Society 60 (12), 2075-2078.

Crouch, C. H., Carey, J. E., Warrender, J. M., Aziz, M. J., Mazur, E., Gnin, F. Y., 2004. Comparison of structure and properties of femtosecond and nanosecond laser-structured silicon. Applied Physics Letters 84 (11), 1850-1852.

Gagliardi, F., 2007. Epistemological justification of test driven development in agile processes. Lecture Notes in Computer Science (including subseries Lecture Notes in Artificial Intelligence and Lecture Notes in Bioinformatics) 4536 LNCS, 253-256.

Gjessing, J., Sudb, A., Marstein, E., 2011. Comparison of periodic lighttrapping structures in thin crystalline silicon solar cells. Journal of Applied Physics 110 (3).

Green, M., 2008. Self-consistent optical parameters of intrinsic silicon at $300 \mathrm{k}$ including temperature coefficients. Solar Energy Materials and Solar Cells 92 (11), 1305-1310.

Green, M. A., Emery, K., Hishikawa, Y., Warta, W., Dunlop, E. D., 2013. Solar cell efficiency tables (version 42). Progress in Photovoltaics: Research and Applications 21 (5), 827-837.

Hapke, B., 2012. Theory of Reflectance and Emittance Spectroscopy. Cambridge University Press.

Hua, X. S., Zhang, Y. J., Wang, H. W., 2010. The effect of texture unit shape on silicon surface on the absorption properties. Solar Energy Materials and Solar Cells 94 (2), 258-262. 
Kelly, N., Gibson, T., 2011. Increasing the solar photovoltaic energy capture on sunny and cloudy days. Solar Energy 85 (1), 111-125.

Lien, S.-Y., Yang, C.-H., Hsu, C.-H., Lin, Y.-S., Wang, C.-C., Wuu, D.-S., 2012. Optimization of textured structure on crystalline silicon wafer for heterojunction solar cell. Materials Chemistry and Physics 133 (1), 63-68.

McIntosh, K. R., Baker-Finch, S. C., 2012. Opal 2: Rapid optical simulation of silicon solar cells. In: Conference Record of the 38th IEEE Photovoltaic Specialists Conference. pp. 265-271.

Moreno, M., Murias, D., Martnez, J., Reyes-Betanzo, C., Torres, A., Ambrosio, R., Rosales, P., Roca i Cabarrocas, P., Escobar, M., 2014. A comparative study of wet and dry texturing processes of c-si wafers for the fabrication of solar cells. Solar Energy 101, 182-191.

Nicodemus, F. E., Richmond, J. C., Hsia, J. J., Ginsberg, I. W., Limperis, T., 1977. Geometrical considerations and nomenclature for reflectance. Natl Bur Stand (US) Monogr (160), 1-52.

Parretta, A., Sarno, A., Tortora, P., Yakubu, H., Maddalena, P., Zhao, J., Wang, A., 1999. Angle-dependent reflectance measurements on photovoltaic materials and solar cells. Optics Communications 172 (1), 139-151.

Parretta, A., Yakubu, H., Ferrazza, F., Altermatt, P. P., Green, M. A., Zhao, J., 2003. Optical loss of photovoltaic modules under diffuse light. Solar Energy Materials and Solar Cells 75 (3-4), 497-505.

Razykov, T., Ferekides, C., Morel, D., Stefanakos, E., Ullal, H., Upadhyaya, H., 2011. Solar photovoltaic electricity: Current status and future prospects. Solar Energy 85 (8), 1580-1608.

Rodríguez, J. M., Tobías, I., Luque, A., 1997. Random pyramidal texture modelling. Solar Energy Materials and Solar Cells 45 (3), 241-253.

Trupke, M., Ramirez-Martinez, F., Curtis, E. A., Ashmore, J. P., Eriksson, S., Hinds, E. A., Moktadir, Z., Gollasch, C., Kraft, M., Prakash, G. V., Baumberg, J. J., 2006. Pyramidal micromirrors for microsystems and atom chips. Applied Physics Letters 88 (7). 
Yang, Y., Green, M., Ho-Baillie, A., Kampwerth, H., Pillai, S., Mehrvarz, H., 2013. Characterization of 2-d reflection pattern from textured front surfaces of silicon solar cells. Solar Energy Materials and Solar Cells 115, $42-51$.

Yoo, J., 2010. Reactive ion etching (rie) technique for application in crystalline silicon solar cells. Solar Energy 84 (4), 730-734.

Yu, Z., Gao, H., Wu, W., Ge, H., Chou, S. Y., 2003. Fabrication of large area subwavelength antireflection structures on si using trilayer resist nanoimprint lithography and liftoff. Journal of Vacuum Science and Technology B: Microelectronics and Nanometer Structures 21 (6), 2874-2877.

Yun, G., Crabtree, K., Chipman, R., 2011. Three-dimensional polarization ray-tracing calculus i: Definition and diattenuation. Applied Optics 50 (18), 2855-2865.

Zhao, J., Wang, A., Green, M. A., Ferrazza, F., 1998. 19.8\% efficient "honeycomb" textured multicrystalline and $24.4 \%$ monocrystalline silicon solar cells. Applied Physics Letters 73 (14), 1991-1993. 

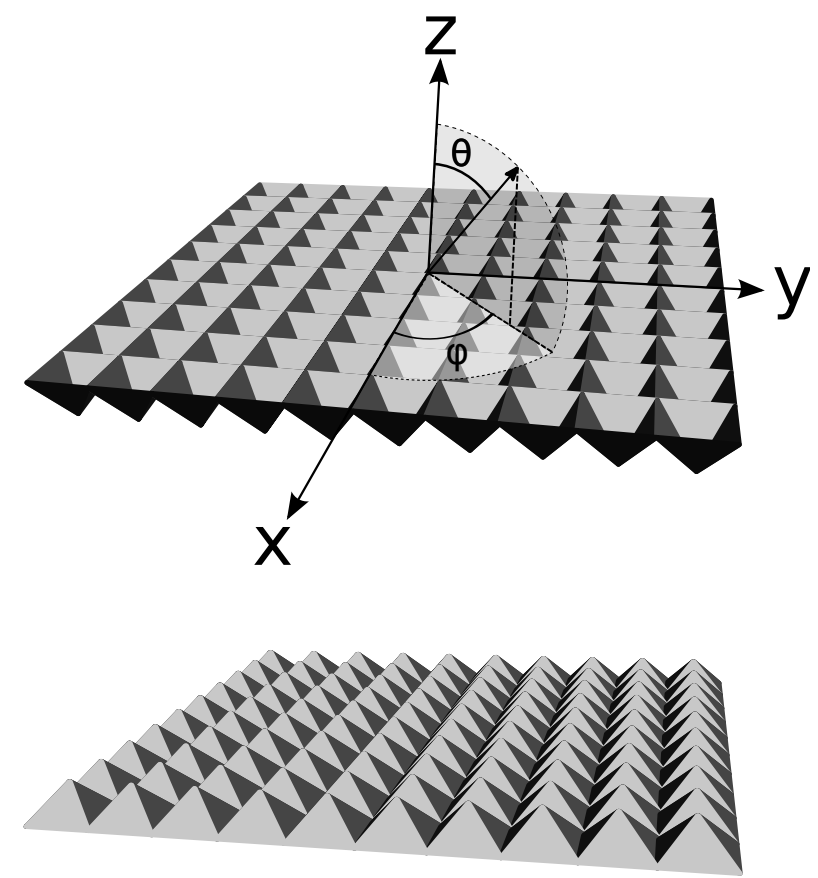

Figure 1: Three-dimensional model of textured surfaces: regular inverted pyramids (top) and upright pyramids (bottom). In the model, the direction of a light ray is defined by the polar angle $\theta$ and the azimuth angle $\phi$. The incidence angle is therefore $\pi-\theta$.

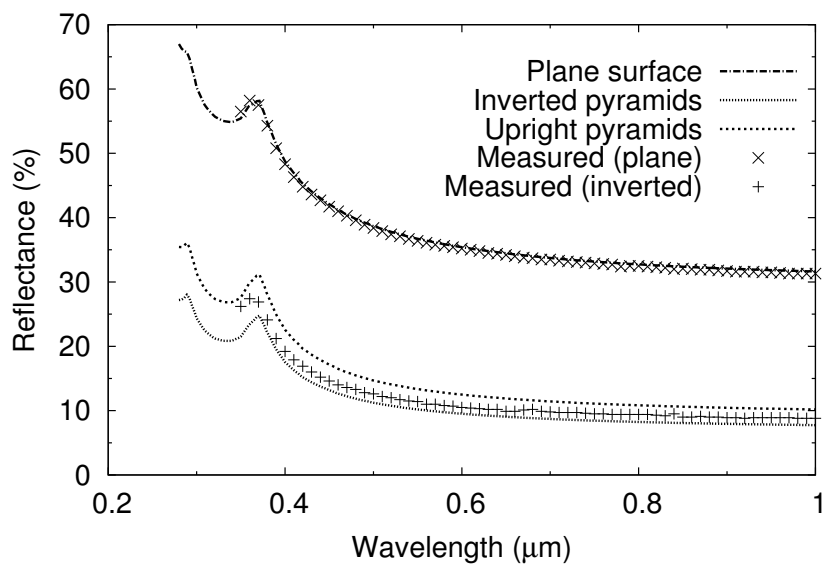

Figure 2: Simulation results for polished silicon, upright and inverted pyramids, and measurements for polished silicon and inverted pyramids. 


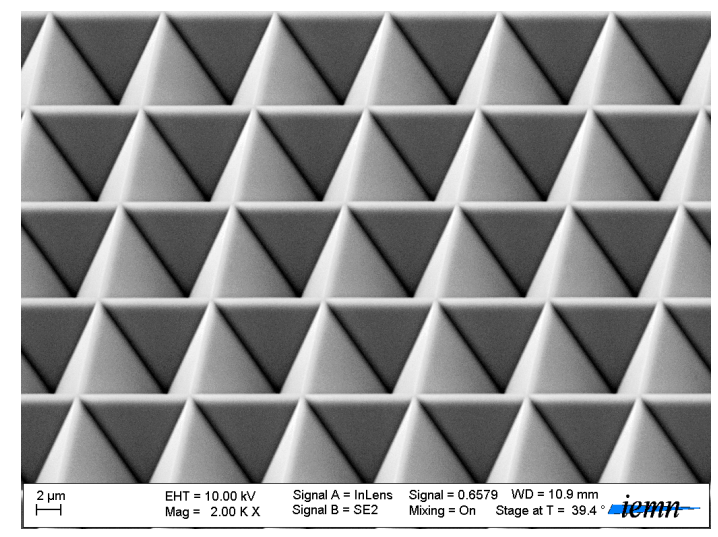

Figure 3: SEM micrographs of inverted pyramids etched on Si.

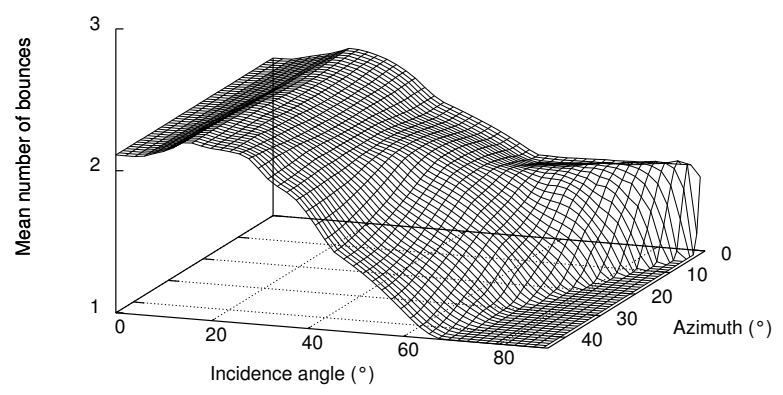

Figure 4: Mean number of reflections on a surface textured with regular upright pyramids versus the azimuth angle and the incidence angle. 


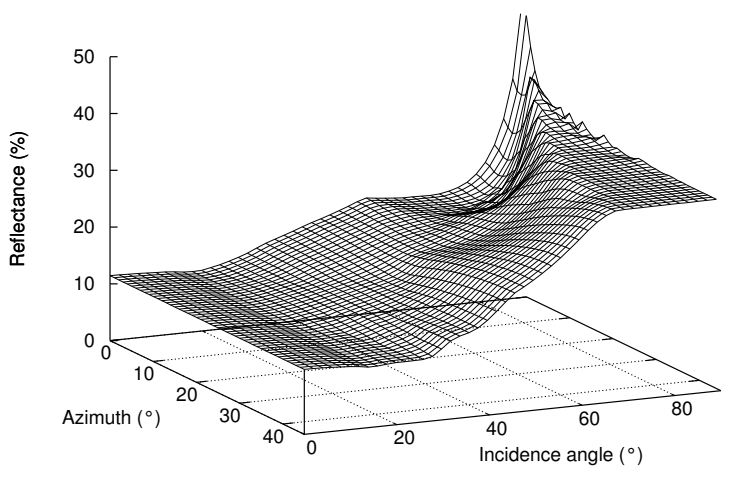

Figure 5: Hemispherical reflectance of a surface textured with regular upright pyramids versus the azimuth angle and the incidence angle at $\lambda=0.7 \mu \mathrm{m}$.

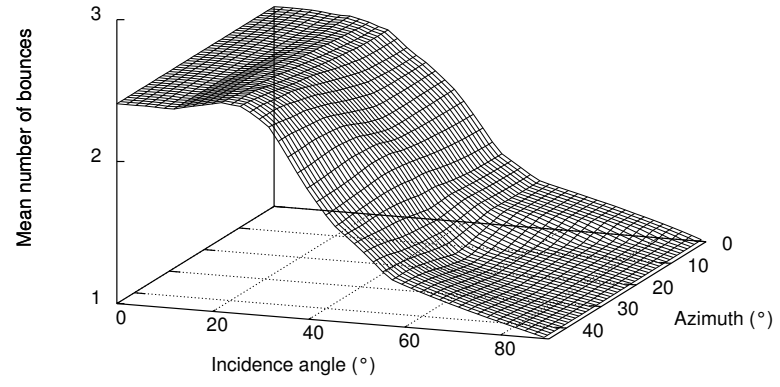

Figure 6: Mean number of reflections on a surface textured with regular inverted pyramids versus the azimuth angle and the incidence angle. 


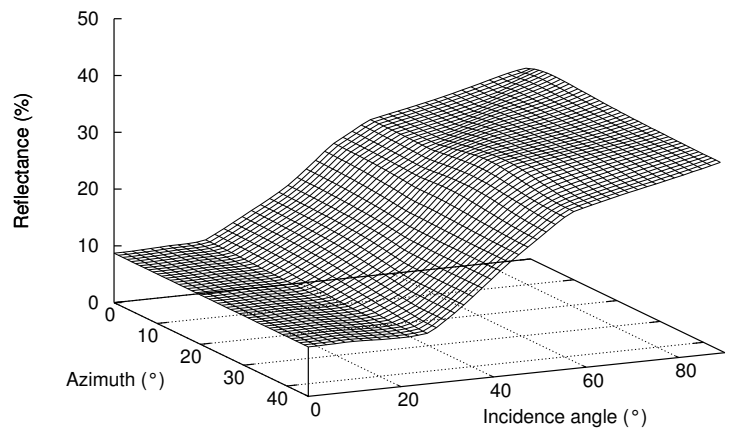

Figure 7: Hemispherical reflectance of a surface textured with regular inverted pyramids versus the azimuth angle and the incidence angle at $\lambda=0.7 \mu \mathrm{m}$.

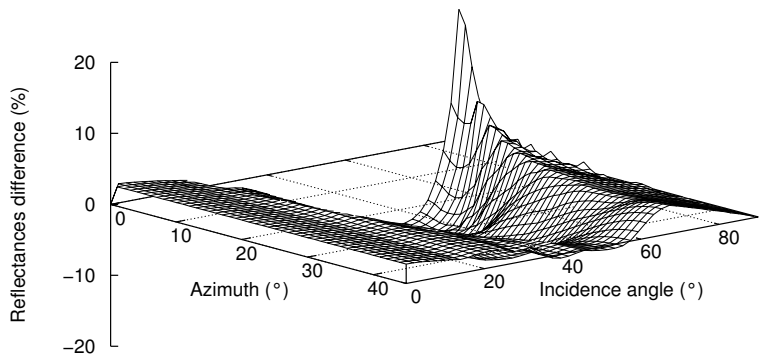

Figure 8: Difference of the reflectances at $\lambda=0.7 \mu \mathrm{m}$ of surfaces textured with upright and inverted pyramids versus the azimuth angle and the incidence angle. 


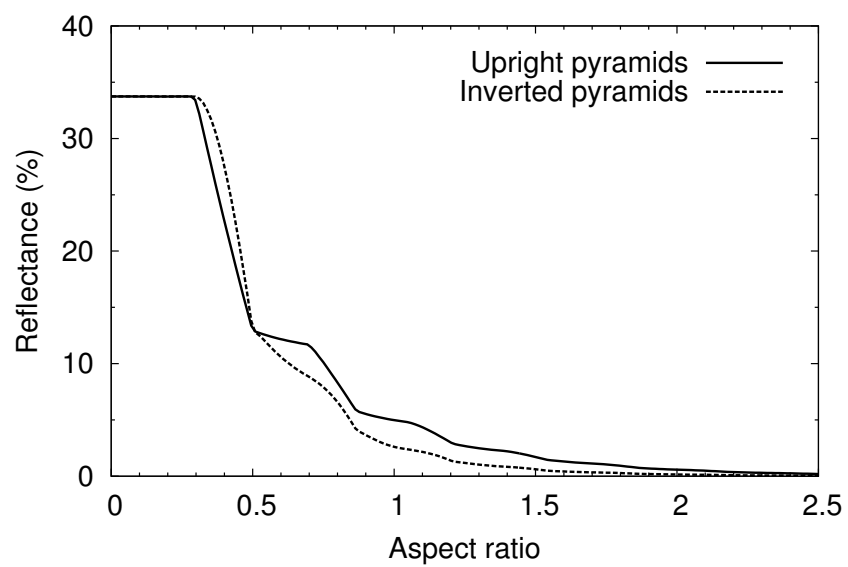

Figure 9: Hemispherical reflectance on a surface textured with regular upright and inverted pyramids versus the pyramids aspect ratio at $\lambda=0.7 \mu \mathrm{m}$.

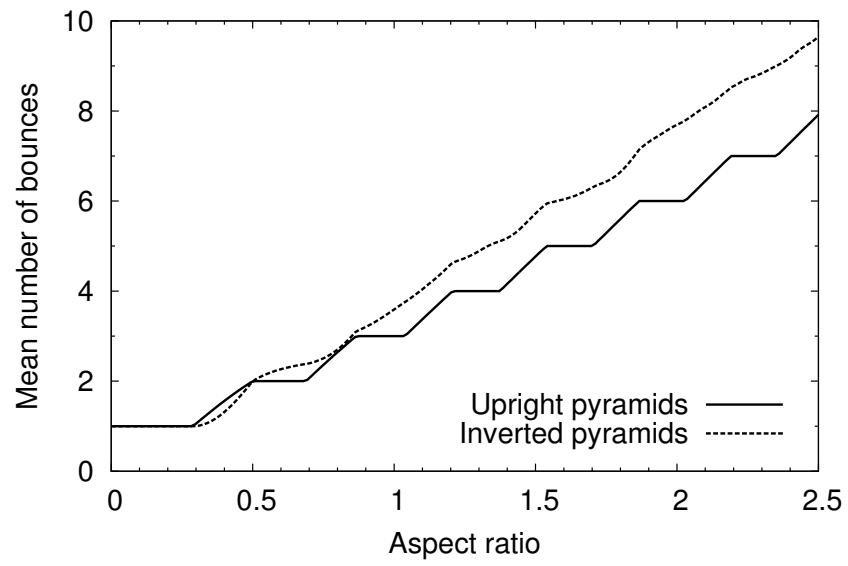

Figure 10: Number of reflections on a surface textured with regular upright or inverted pyramids versus the pyramid aspect ratio. 